\title{
Total Recovery of Gold Contained in Computer Printed Circuit Boards. Leaching Kinetics of $\mathrm{Cu}, \mathrm{Zn}$ and $\mathrm{Ni}$
}

\author{
María Isabel Reyes, ${ }^{1}$ Isauro Rivera, ${ }^{1 *}$ Francisco Patiño, ${ }^{1}$ Mizraim U. Flores, ${ }^{1}$ and Martín Reyes ${ }^{1}$ \\ 1 Área Académica de Ciencias de la Tierra y Materiales, UAEH, Ciudad Universitaria Carretera Pachuca-Tulancingo Km. 4.5, \\ C.P. 42184, Pachuca, Hidalgo.
}

Received October 13, 2011; accepted March 6, 2012

\begin{abstract}
In this study a thorough characterization of certain printed circuit boards has been carried out; it was found that they are made up of a polymer layer, a metal layer of $\mathrm{Cu}, \mathrm{Zn}$ and $\mathrm{Ni}$, and a gold substrate. A kinetic study of the acid dynamic leaching of copper, zinc and nickel has been carried out, finding out that these elements' dissolution allows the gold substrate to be physically separated; then, the gold particles are separated from the polymer by filtration. The reaction orders were calculated vs. $\mathrm{H}_{2} \mathrm{SO}_{4}$ concentration, and the activation energy was calculated as well; reaction orders of $n=0.265, n=0.247$ and $n=0.245$ were found for $\mathrm{Cu}, \mathrm{Zn}$ and Ni respectively, while $\mathrm{Ea}=$ 86.3, $\mathrm{Ea}=95.3$ and $\mathrm{Ea}=11.2 \mathrm{~kJ} / \mathrm{mol}$ were found for $\mathrm{Cu}, \mathrm{Zn}$ and $\mathrm{Ni}$ respectively. When the attack time is over, a shiny, solid product has been obtained; it was characterized by SEM-EDS and AAS, confirming that it is metallic gold, with a purity of 100 and $99.9 \%$ according to the respective technique.
\end{abstract}

Key words: Gold, printed circuit boards, kinetics, leaching, recovery.

\section{Introduction}

At a fast rate, recycling is increasingly being considered by the developed countries. During a period of time they mainly focused on the recycling of post-consumed products. The recycling of industrial waste is also tending to increase. With some materials, an effective recycling system cannot be spontaneously installed, and therefore it has become a subject concerning technology, planning, economy and environmental regulation [1]. Gold and silver are examples of industrial materials that can be recycled $[2,3,4]$. The gold is used in aqueous and metallic form; its solid wastes consist of used chips, gold pieces and filings [5]. Electronic waste consists basically of computer components, electronic boards, electrical appliances, cellphones, audio equipment, etc. Specifically, the gold-containing electronic wastes are constituted by printed circuit boards. In wide zones, usually a gold layer is placed on a substrate of a less noble metal, like copper, zinc or nickel, which is inserted on a polymer base. The gold contained in these printed circuit boards is of high commercial interest; it is present in amounts ranging from 0.1 to 0.5 grams of gold per board. In Mexico around 5 million computers are disposed of every year [6]. This enormous potential source is evident, but it is disposed of or partially recovered by very rare, imported and expensive processes. Such processes include mechanical and metallurgical operations, which usually generate considerable amounts of polluting gases.

The need for approaching research on precious metals recovery from electronic wastes is evident, specifically on the recovery of gold contained in the printed circuit boards; the
Resumen. En el presente estudio se ha desarrollado una exhaustiva caracterización de ciertos circuitos impresos de computadoras, encontrando que están constituidos por una capa polimérica, una capa metálica de $\mathrm{Cu}, \mathrm{Zn}$, Ni y un sustrato de oro. Se ha realizado un estudio cinético de la lixiviación dinámica ácida de cobre, zinc y níquel, cuya disolución permite la separación física del sustrato de oro, respecto a la capa polimérica; posteriormente y por filtración las partículas de oro son separadas del polímero. Se calcularon los órdenes de reacción frente a la concentración de $\mathrm{H}_{2} \mathrm{SO}_{4}$, así como la energía de activación del sistema; encontrando que $n=0.265, n=0.247$ y $n=0.245$ para el $\mathrm{Cu}, \mathrm{Zn}$ y Ni respectivamente. Por otra parte, la $\mathrm{Ea}=86.3, \mathrm{Ea}=95.3$ y Ea $=11.2 \mathrm{~kJ} / \mathrm{mol}$ para el $\mathrm{Cu}, \mathrm{Zn}$ y Ni respectivamente. Al finalizar el tiempo de ataque se ha obtenido un producto sólido brillante, que fue caracterizado por SEM-EDS y AAS confirmando que el mismo se trata de oro metálico con una pureza del 100 y $99.9 \%$ según la técnica respectiva.

Palabras clave: Oro, circuitos impresos, cinética, lixiviación, recuperación.

amount of gold contained in the electronic wastes can be even higher than the amount present in an ore. Therefore, the secondary sources of metals are increasingly becoming attractive. The research works carried out in order to recover precious metals contained in electronic waste are frankly scarce $[5,7$, 8-12]. On the subject, E. Morera [9] has studied the leaching of metals with ozone, finding that, in $\mathrm{Cl}-\mathrm{O}_{3}$ media, it is possible to dissolve the contained copper, nickel, tin, gold and silver; however, its use at an industrial level is not very clear, because the investment costs for ozone generation are a limiting factor, without mentioning the necessity of leaching the metals by stages. J. Viñals, et.al. [13] have studied the leaching of gold and palladium with aqueous ozone in chloride media dissolution, where the gold and palladium recycling from metallic wastes can be carried out by ozoneleaching at room temperature and at low concentrations $(\sim 0.1$ $\left.\mathrm{M} \mathrm{H}^{+} \mathrm{y} \mathrm{Cl}^{-}\right)$. Rh and Pt remain unreactive, while metals, such as $\mathrm{Cu}, \mathrm{Ni}, \mathrm{Ag}$ can be previously eliminated through a $\mathrm{O}_{2} / \mathrm{H}^{+}$ medium and $\mathrm{O}_{2} / \mathrm{O}_{3} / \mathrm{H}^{+}$leaching pretreatments. Gold and palladium are dissolved in $\mathrm{O}_{3} / \mathrm{Cl}^{-} / \mathrm{H}^{+}$, with formation of $\mathrm{AuCl}$ and $\mathrm{PdCl}$. On the other hand, the leaching studies showed a passive region, located basically at $>0.01$ and $<0.05 \mathrm{M} \mathrm{Cl}^{-}$ for $\mathrm{Au}$ and $\mathrm{Pd}$ respectively. In the non-passive region, rates slightly depend on $\mathrm{H}^{+}$and $\mathrm{Cl}^{-}$. The secondary formation of chlorine and hypochlorites was irrelevant $\left(\leq 0.1 \mathrm{M} \mathrm{Cl}^{-}\right)$. Kinetics were controlled by mass transfer of $\mathrm{O}_{3(\mathrm{aq})}$ to the solid-liquid interface, obtaining a first order dependence with respect to $\left[\mathrm{O}_{3}\right]_{\mathrm{aq}}$. The leaching rate of gold gradually decreased to $\mathrm{pH}$ $>2$ as a consequence of the influence of the transfer control of $\left[\mathrm{H}^{+}\right]$. 
In this work, we propose to recover the gold contained in the printed circuit boards by means of acid dynamic leaching using oxygen and sulfuric acid to dissolve the copper, zinc and nickel substrate. This will allow the physical separation of the gold and of the polymer component; then, by filtration, the gold particles will be separated by sieving the polymer, the proposed process is innovative and original. Finally, the particles are washed and ready to be cast into gold ingots. We studied the effect of the sulfuric acid concentration on the leaching rate of the base metals, and we calculated the order of the reaction of the sulfuric acid on each base metal.

\section{Results and discussion}

The computer printed circuit boards were characterized by SEM-EDS. Figure 1a shows images of the printed circuit
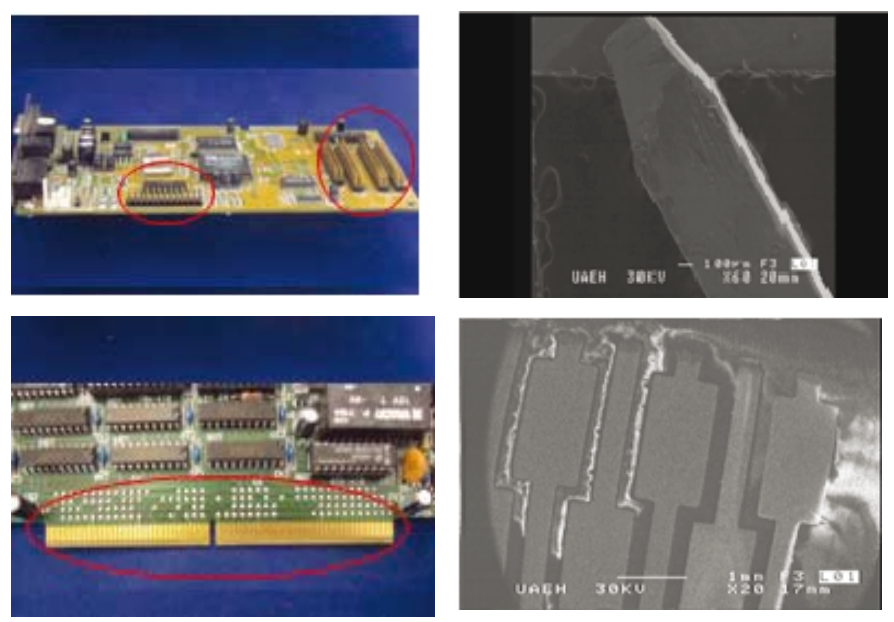

a)

b)

Fig. 1. a) Photograph of the printed circuit boards indicating the zone selected for analysis, b) SEM photograph of the selected zone.

Table 1. Table of the data obtained from the piece analyzed by EDS.

\begin{tabular}{cccccc}
\hline \multicolumn{5}{c}{ PROZA Correction Acc.Volt. $=30 \mathrm{kV}$ Take-off } \\
\hline \multicolumn{5}{c}{ Angle $=42.73 \mathrm{deg}$ Number of Iterations $=4$} \\
\hline Element & k-ratio & ZAF & Atom \% & Element & Wt \% Err. \\
\hline Zn-K & (calc.) & & & Wt \% & (1-Sigma) \\
$\mathrm{Cu}-\mathrm{K}$ & 0.0315 & 0.843 & 5.28 & 2.66 & $+/-0.41$ \\
$\mathrm{Fe}-\mathrm{K}$ & 0.0010 & 0.956 & 0.22 & 0.09 & $+/-0.11$ \\
$\mathrm{Sn}-\mathrm{L}$ & 0.0000 & 1.829 & 0.00 & 0.00 & $+/-0.00$ \\
$\mathrm{Au}-\mathrm{L}$ & 0.7104 & 1.087 & 50.93 & 77.19 & $+/-1.85$ \\
$\mathrm{Ag}-\mathrm{L}$ & 0.0000 & 1.990 & 0.00 & 0.00 & $+/-0.00$ \\
$\mathrm{Pd}-\mathrm{L}$ & 0.0001 & 2.237 & 0.04 & 0.03 & $+/-0.29$ \\
Total & & & 100.00 & 100.00 & \\
\hline
\end{tabular}

boards, indicating the zone selected for analysis. Figure $1 \mathrm{~b}$ shows a micrograph of the selected zone; it can be observed that the pieces present a bar-like morphology; these pieces were analyzed by SEM-EDS. The results of the analysis are shown in table 1 and in figure 2, where it can be observed that the gold content is $77.19 \%$; other elements, such as $\mathrm{Cu}, \mathrm{Zn}$ and $\mathrm{Ni}$ are present as well. The pieces were used for carrying out the kinetic study, where we evaluated the concentration of sulfuric acid; this parameter was varied, while the other parameters were kept constant. The experimental conditions of the study are the following: $\left[\mathrm{H}_{2} \mathrm{SO}_{4}\right][\mathrm{M}]=0.013,0.025,0.050,0.076$, 0.102 and 0.204 . Constant parameters: Solution volume: 500 $\mathrm{mL}$; Temperature: $25{ }^{\circ} \mathrm{C}$; Stirring rate: $750 \mathrm{~min}^{-1}$; Oxygen partial pressure: $1 \mathrm{~atm}$; Sample mass: $10 \mathrm{~g}$. The acid concentrations, at the different studied molarities, were kept constant by monitoring and measuring the $\mathrm{pH}$ value of the leaching solution, and by adding the necessary amount of acid in order to keep the initial $\mathrm{H}_{2} \mathrm{SO}_{4}$ concentration.

When graphically representing the leached ppm of the dissolved metal in function of time, we obtain a slope whose value is the rate experimental constant $\left(\mathrm{K}_{\text {exp }}\right)$ for each studied concentration of sulfuric acid. Figure 3 graphically represents the logarithm of $\mathrm{K}_{\text {exp }}$ vs. The logarithm of the several analyzed $\left[\mathrm{H}_{2} \mathrm{SO}_{4}\right]$; we have calculated the reaction order $(n)$ of such vales, obtaining a value of $n=0.265$ for copper. Figure 4

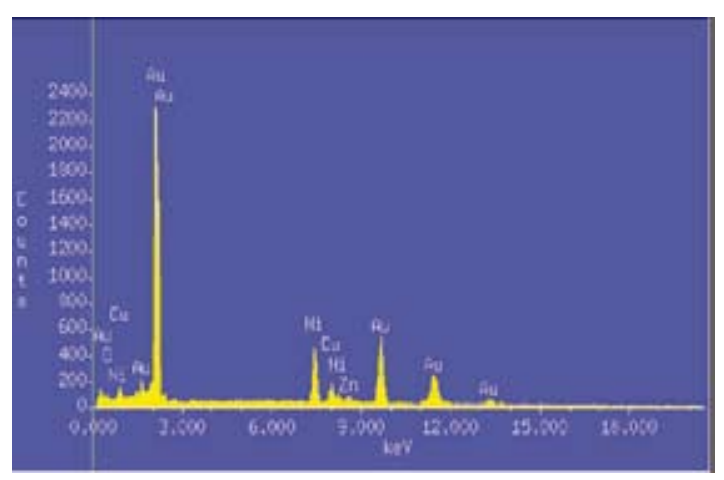

Fig. 2. EDS spectrum of the analyzed piece.

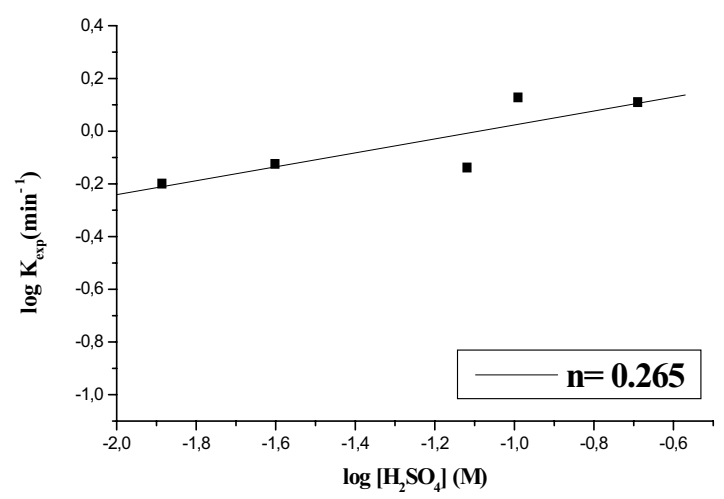

Fig. 3. Graphical representation of the dependence of the $\mathrm{K}_{\exp } \mathrm{vs}$. sulfuric acid concentration. Copper. Reaction time 0-240 minutes. $n$ $=0.265$. 
shows the logarithm of $\mathrm{K}_{\text {exp }}$ vs. the logarithm of the different $\left[\mathrm{H}_{2} \mathrm{SO}_{4}\right]$; the value of the reaction order is calculated and $n=$ 0.247 is obtained for zinc. In a similar fashion, figure 5 presents the logarithm of $\mathrm{K}_{\text {exp }}$ vs. the logarithm of the several analyzed $\left[\mathrm{H}_{2} \mathrm{SO}_{4}\right]$; a value of $n=0.245$ is obtained for nickel. These results show that, under the studied conditions, the $\left[\mathrm{H}_{2} \mathrm{SO}_{4}\right]$ has a considerable influence on the leaching rate of copper, zinc and nickel. Once the base metals were leached, that is, after 240 minutes of the reaction, time, we could obtain, by filtration, gold particles that were subsequently characterized. Once the reaction orders were calculated, the activation energy of the system was also calculated; for this purpose, a series of experiments was carried out, with temperature as the variable parameter: $15,20,25,35,40$ and $50\left({ }^{\circ} \mathrm{C}\right)$. The other parameters were kept constant. In this case, the experimental conditions are the following: Solution volume: $500 \mathrm{~mL}$; Sulfuric acid concentration: $0.076 \mathrm{M}$; Stirring rate: $750 \mathrm{~min}^{-1}$; Oxygen partial pressure: $1 \mathrm{~atm}$; Sample mass: $10 \mathrm{~g}$. To control the temperature we used a thermocouple connected to a heating plaque and magnetic stirring. The thermocouple allows to control and to keep the bath temperature constant, with tolerances of $\pm 0.2^{\circ} \mathrm{C}$. When graphically representing the leached ppm of each metal

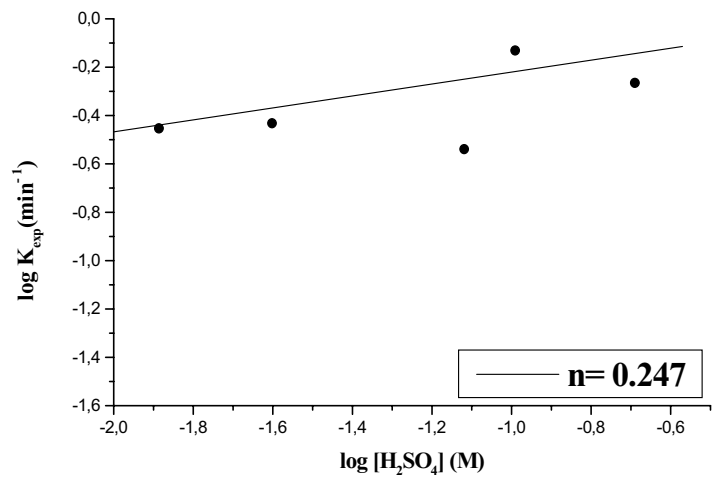

Fig. 4. Graphical representation of the dependence of the $K_{\exp }$ vs. sulfuric acid concentration. Zinc. Reaction time 0-240 minutes. $n=$ 0.247 .

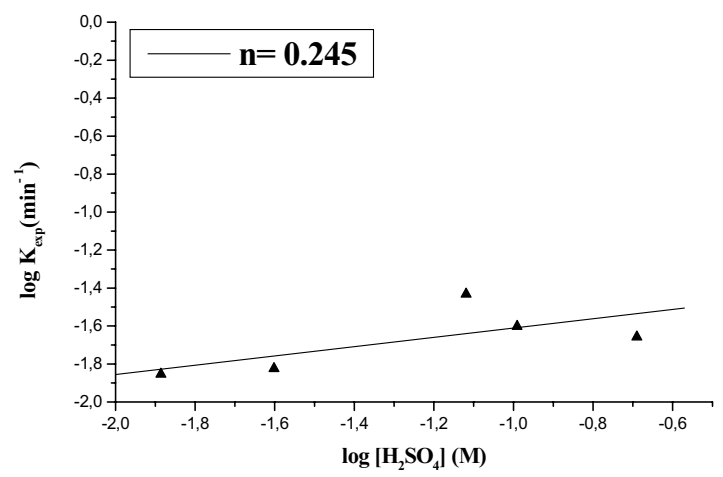

Fig. 5. Graphical representation of the dependence of the $\mathrm{K}_{\text {exp }}$ vs. sulfuric acid concentration. Nickel. Reaction time 0-240 minutes. $n$ $=0.245$. dissolved in function of time, we obtain a slope whose value is the $\mathrm{K}_{\exp }$ of rate for each studied temperature. The activation energy of the system was calculated according to the Arrhenius equation. Figure 6 presents the $\ln$ vs. 1/T for copper, resulting in a straight line with negative slope, whose value is equal to $-\mathrm{Ea} / \mathrm{R}$; this allows to calculate the Ea for copper: $\mathrm{Ea}=86.3$ $\mathrm{kJ} / \mathrm{mol}$. Figure 7 presents the $\ln$ vs. $1 / \mathrm{T}$ for zinc, resulting in a straight line with negative slope, which allows, like in the previous case, to calculate the activation energy of the system for zinc: $\mathrm{Ea}=95.3 \mathrm{~kJ} / \mathrm{mol}$. Figure 8 presents the $\ln \mathrm{vs} .1 / \mathrm{T}$ for nickel, calculating the activation energy of the system for this

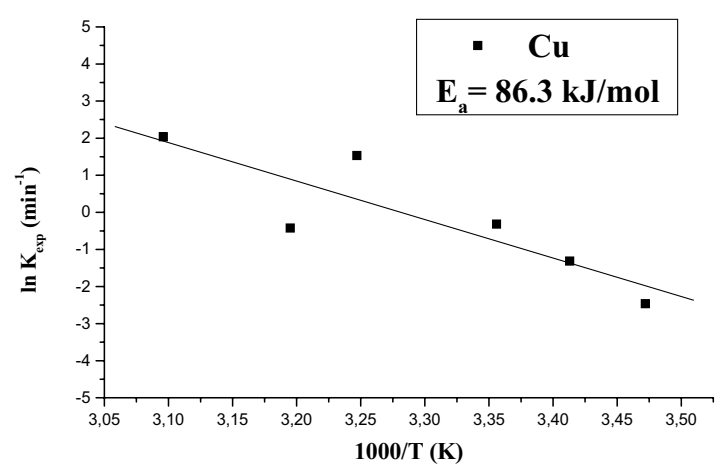

Fig. 6. Graphical representation of the dependence of the $K_{\exp }$ vs. temperature. Copper. Reaction time 0-240 minutes. $\mathrm{Ea}=86.3 \mathrm{~kJ} / \mathrm{mol}$.



Fig. 7. Graphical representation of the dependence of the $K_{\exp }$ vs. temperature. Zinc. Reaction time 0-240 minutes. $\mathrm{Ea}=95.3 \mathrm{~kJ} / \mathrm{mol}$.



Fig. 8. Graphical representation of the dependence of the $K_{\text {exp }}$ vs. temperature. Nickel. Reaction time 0-240 minutes. Ea $=11.2 \mathrm{~kJ} / \mathrm{mol}$. 
metal: $\mathrm{Ea}=11.2 \mathrm{~kJ} / \mathrm{mol}$. It is very clear [14] that, in the case of the leaching of $\mathrm{Cu}$ and $\mathrm{Zn}$, there is a chemical control (observed in the values higher than $40 \mathrm{~kJ} / \mathrm{mol}$ ); in the case of $\mathrm{Ni}$, there is a control by diffusion or transport.

In most of the cases, upon finishing the experiment, we obtained a gold solid product that is completely separated from the samples. The amount of recovered gold depend on the experimental conditions, obtaining in some cases of recoveries $99.5 \%$ (7.68 $\mathrm{g}$ of $\mathrm{Au} / 10 \mathrm{~g}$ sample mass) and under next conditions: Solution volume: $500 \mathrm{~mL}$; Temperature: $50^{\circ} \mathrm{C}$; Sulfuric acid concentration: $0.076 \mathrm{M}$; Stirring rate: $750 \mathrm{~min}^{-1}$; Oxygen partial pressure: $1 \mathrm{~atm}$; Attack time: 240 minutes; Sample mass: 10 g. Figure 9 shows the products of the leaching of the printed circuit boards' samples; it can be seen how the golden coating is separated from the metal layer that has passed to the solution and from the polymer layer. Figure 10 is an SEM-EDS image of the obtained solid product, confirming that it is metallic gold. Table 2 shows the data of the chemical analysis by SEM-EDS of the obtained product; with this technique, the purity of $100 \%$ gold clearly stands out. The obtained solid product was also characterized by AAS, and a purity of $99.9 \%$ was obtained. It is worth noting that the $\mathrm{Cu}, \mathrm{Zn}$ and $\mathrm{Ni}$ present in the leaching solution can be recovered by any of the conventional procedures used for obtaining these metals.



Fig. 9. Products of the acid dynamic leaching of golden components. Total reaction time $240 \mathrm{~min}$.



Fig. 10. SEM-EDS image of the golden product, confirming that it actually is metallic gold.

\section{Conclusions}

The gold was characterized by SEM-EDS and AAS, obtaining purities of $100 \%$ and $99.9 \%$ with the respective techniques. At attack times of 240 minutes, the total of $\mathrm{Cu}, \mathrm{Zn}$ and $\mathrm{Ni}$ passes to the leaching solution, and a total physical separation of the gold substrate and the polymer layer is achieved. A kinetic study of the leaching of $\mathrm{Cu}, \mathrm{Zn}$ and $\mathrm{Ni}$ was carried out, and it was found that the reaction orders are of $n=0.265,0.247$ and 0.245 respectively. The activation energies are of $\mathrm{Ea}=86.3$, $\mathrm{Ea}=95.3$ and $\mathrm{Ea}=11.2 \mathrm{~kJ} / \mathrm{mol}$ respectively.

Table 2. Table of the data of the chemical analysis by SEM-EDS of the obtained product.

\begin{tabular}{cccccc}
\hline Element & k-ratio & ZAF & Atom \% & Element & Wt \% Err. \\
\hline & (calc.) & & & Wt \% & (1-Sigma) \\
Au-L & 1.0000 & \multirow{2}{*}{1.000} & 100.00 & 100.00 & $+/-3.11$ \\
Total & & & 100.00 & 100.00 & \\
\hline
\end{tabular}

\section{Experimental procedure}

The methodology of this research work comprised a series of experiments performed in the following sequence: A) Collection of computer printed circuit boards. B) Meticulous characterization by SEM-EDS of all the parts that form the printed circuit boards. C) Selection of the parts containing gold. D) Cutting of the selected pieces containing gold. E) Determination of the leaching conditions with the object of studying the nature of the leaching reaction of the base metals (copper, zinc and nickel) that form the contained gold's metal substrate. All the leaching experiments were carried out at atmospheric pressure in a conventional $500 \mathrm{~mL}$ glass kettle. It was mounted on a heating plaque equipped with magnetic stirring, temperature control and stirring rate meter. The $3 \mathrm{~cm}$-long stirrer is made of steel covered with Teflon. A continuous $\mathrm{pH}$ measuring system was established, using a $\mathrm{pH}$-meter equipped with a $\mathrm{pH}$ electrode capable of operating under extreme conditions of acidity and alkalinity. The temperature of the system was controlled by a thermometer submerged in the solution (for the tests carried out at room temperature). For the tests performed at high temperatures, the control was carried out by means of a thermoregulator that controlled and kept the bath's temperature constant, with tolerances of $\pm 0.2^{\circ} \mathrm{C}$. The medium of attack was oxygen-sulfuric acid. F) Development of the leaching kinetics of the base metals. This means determining the factors that affect the leaching rate of such metals. The evaluated effects are sulfuric acid concentration $(0.013,0.025,0.050,0.076,0.102$ and $0.204 \mathrm{M})$ and temperature $\left(15,20,25,35,40\right.$, y $\left.50{ }^{\circ} \mathrm{C}\right)$.

Finally, the reaction orders and activation energies were calculated; they are kinetic parameters of great importance for 
the industrial application of the gold recovery process. The samples taken at different reaction times were analyzed by Atomic Absorption Spectrophotometry (AAS). The obtained solid product was characterized by Scanning Electron Microscopy-Energy Dispersive Spectroscopy (SEM-EDS) and AAS.

\section{Acknowledgements}

The authors would like to thank the CONACYT for the Retention project 117052 of Dr. María Isabel Reyes Valderrama 2009-2010. They would also like to thank the project FOMIXHGO-2008-C01-97579 and the PROMEP.

\section{References}

1. Kimbrough, D.E.; Wong, W.P.; Kim, J. J. Solid Waste Technol. Manage 1996, 23, 197-207.

2. Rivera, I. PhD Thesis. Estudio cinético de la precipitación/lixiviación de plata en el sistema $\mathrm{O}_{2-}-\mathrm{S}_{2} \mathrm{O}_{3}{ }^{2-}-\mathrm{S}_{2} \mathrm{O}_{4}{ }^{2-}$. Aplicación en efluentes industriales. Universitat de Barcelona, Spain, 2003.

3. Rivera, I.; Patiño, F.; Cruells, M.; Roca, A.; Viñals, J. Rev. Metal. 2004, 40, 369-373.
4. Rivera, I.; Patiño, F.; Salinas, E.; Cardoso, E.; Hernández, L. XL Congreso Mexicano de Química. Rev. Soc. Quím. Méx. 2005, 49, 107.

5. Ramírez, J. B.Sc. Thesis. Recuperación de oro a partir de la chatarra electrónica. Universidad Autónoma del Estado de Hidalgo, México, 2008.

6. Gómez, A. J. B.Sc. Thesis. Lixiviación electroquímica de metales preciosos de algunos componentes provenientes de aparatos eléctricos y electrónicos. Universidad Autónoma del Estado de Hidalgo, México, 2007.

7. Sánchez, M. B.Sc. Thesis. Cinética de lixiviación de Cu, Zn y Ni, contenidos en circuitos impresos de computadora. Recuperación de oro. Universidad Autónoma del Estado de Hidalgo, México, 2010.

8. Reyes, M.; Mejía, M.; Rivera, I.; Patiño, F. Bol. Soc. Quím. Méx. 2010, 71, 4 .

9. Morera, E. Ph.D. Thesis. Lixiviación de metales con ozono acuoso. Cinética de la plata y el oro. Aplicaciones. Universitat de Barcelona, Spain, 2004.

10. He, W.; Li, G. J. Hazard. Mater. 2006, 136, 502-512.

11. Cui, J.; Zhang, L. J. Hazard. Mater. 2008, 158, 228-256.

12. Ha, V.; Lee, J.; Jeong, J.; Hai, H.; Jha, M. J. Hazard. Mater. 2010 , 178, 1115-1119.

13. Viñals, J.; Juan, E.; Ruiz, M.; Ferrando, E.; Cruells, M.; Roca, A.; Casado, J. Hydrometallurgy 2006, 81, 142-151.

14. Ballester, A.; Verdeja, L.; Sancho, J. Metalurgia Extractiva. Fundamentos, Síntesis, Madrid, 1999; pp 173. 